\title{
Erratum to: Effects of Twenty Days of the Ketogenic Diet on Metabolic and Respiratory Parameters in Healthy Subjects
}

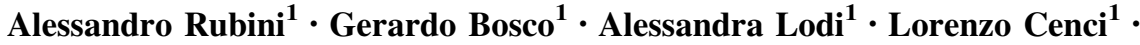 \\ Andrea Parmagnani $^{1} \cdot$ Keith Grimaldi $^{2} \cdot$ Yang Zhongjin $^{3} \cdot$ Antonio Paoli $^{1}$
}

Published online: 1 November 2016

(C) Springer Science+Business Media New York 2016

\section{Erratum to: Lung (2015) 193:939-945}

DOI 10.1007/s00408-015-9806-7

In the original publication of the article, the given and family names of all the authors were swapped. This has been corrected with this erratum.

The online version of the original article can be found under doi:10.1007/s00408-015-9806-7.

Yang Zhongjin

Yangz@upstate.edu

1 Department of Biomedical Sciences, University of Padova, 35131 Padua, Italy

2 Biomedical Engineering Laboratory, University of Athene, 15773 Athens, Greece

3 The Institute for Human Performance, SUNY Upstate Medical University, Syracuse, NY 13210, USA 